\title{
Endoscopic ultrasound-guided pancreaticogastrostomy in a pediatric patient
}

A 14-year-old boy was admitted for acute pancreatitis secondary to pancreas divisum. The patient failed to improve with conservative management. In addition, two separate conventional endoscopic retrograde cholangiopancreatographies (ERCPs) were attempted for endoscopic stenting for pancreas divisum. However both were unsuccessful in cannulation of the pancreatic duct despite secretin injection, spraying of the papilla with methylene blue, and precut minor papillotomy. Despite pancreatic rest and nutritional supplementation via percutaneous endoscopic gastrostomy (PEG) with jejunal extension, the patient had persistent abdominal pain and back pain, as well as failure to thrive. Therefore an endoscopic ultrasound (EUS)-guided pancreaticogastrostomy was performed for pancreatic duct drainage ( $\vee$ Video 1 ). A 7-Fr $\times$ $15-\mathrm{cm}$ plastic double-pigtail stent was placed in antegrade fashion, with the proximal end in the stomach and the distal end in the small intestine ( $\mathbf{F i g . 1}$ ). The post-procedure course was complicated by a peripancreatic collection that

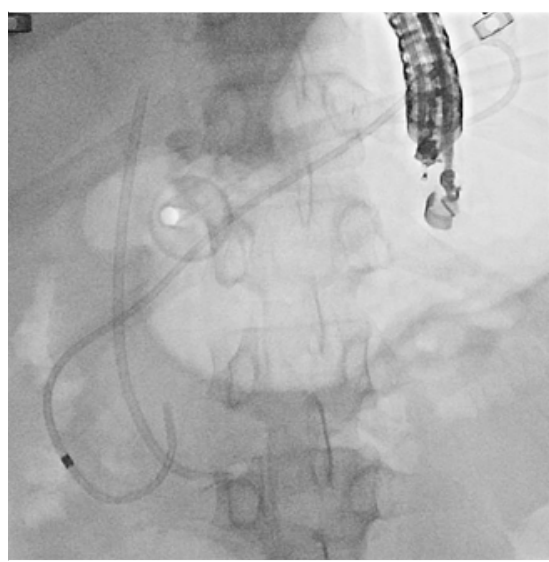

- Fig. 1 Fluoroscopic image of pancreaticogastrostomy in a 14-year-old boy with pancreas divisum, showing the doublepigtail plastic pancreatic duct drainage stent as well as the previously placed biliary stent and percutaneous endoscopic gastrostomy (PEG). was drained with a lumen-apposing metal stent (LAMS). Nevertheless, 1 month after successful pancreatic duct drainage, the patient's abdominal pain had resolved.

Interventional EUS is a rapidly expanding field, and it has become a key technique in therapeutic endoscopy. It was initially described for the management of pancreatic fluid collections, but has expanded to include drainage of the biliary and pancreatic duct in the setting of failed conventional ERCP [1,2]. EUS-guided drainage should not be used to compensate for a lack of ERCP skills [3]. But if conventional drainage has been appropriately attempted and failed, rather than risk a complication from ERCP, then EUS-guided drainage should be performed. We present the first reported case of EUSguided pancreaticogastrostomy in a pediatric patient after failed ERCP for management of pancreas divisum.

Endoscopy_UCTN_Code_CCL_1AF_2AZ_3AD

\section{Competing interests}

M. Kahaleh has received research grants from BSC, Xlumena, Cook, Olympus, Merit Endotek, Aspire Bariatrics, Gl Dynamics, Apollo, Fuji, Pentax, Emcision, Concordia, MI Tech, Maunakea Tech, Ninepoint Medical, W.L. Gore, and the American Society for Gastrointestinal Endoscopy (ASGE).

The Authors

Monica Saumoy, Ming Ming Xu, Amy Tyberg, Michel Kahaleh

Division of Gastroenterology and Hepatology New York Presbyterian Hospital, Weill, Cornell Medical College, New York, USA

\section{Corresponding author}

\section{Michel Kahaleh, MD}

Division of Gastroenterology \& Hepatology, Weill Cornell Medical College New York, NY 10021, USA

Fax: +1-646-962-0110

mkahaleh@gmail.com
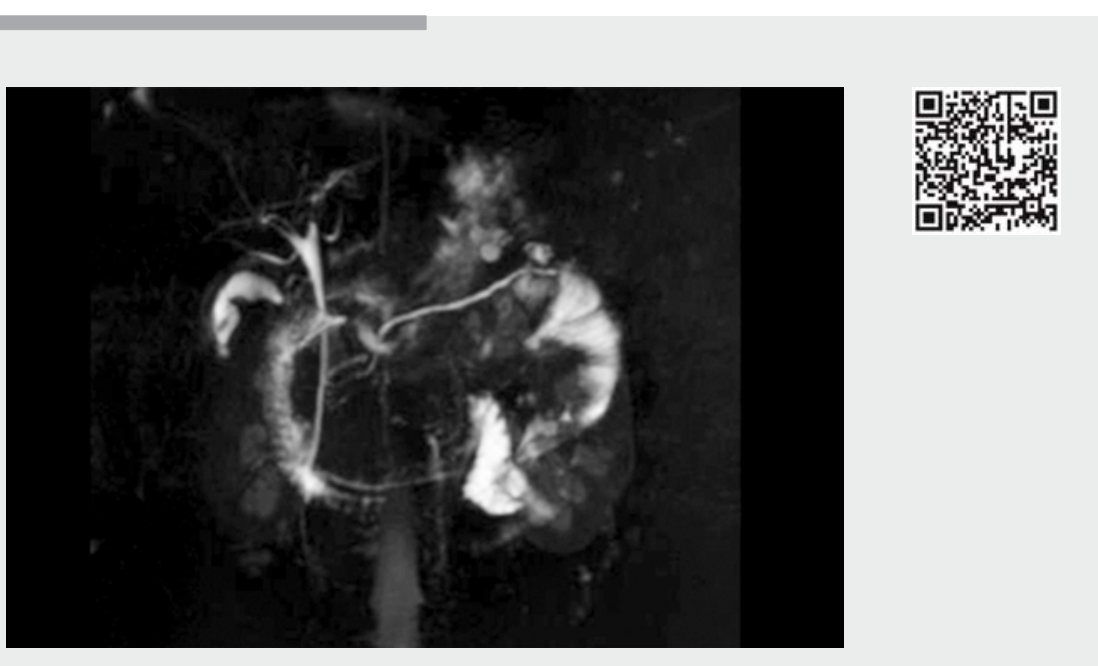

$\checkmark$ Video 1 Failed pancreatic duct cannulation by conventional endoscopic retrograde cholangiopancreatography (ERCP) and successful endoscopic-ultrasound (EUS)-guided pancreatic duct drainage in a 14 -year-old boy with pancreas divisum. MRCP, magnetic resonance cholangiopancreatography; LAMS, lumen-apposing metal stent; PEG-J, percutaneous endoscopic gastrostomy (PEG) with jejunal extension; CBD, common bile duct; PD, pancreatic duct. 


\section{References}

[1] Baron TH. Endoscopic drainage of pancreatic fluid collections and pancreatic necrosis. Gastrointest Endosc Clin N Am 2003; 13: $743-764$

[2] Sharaiha RZ, Khan MA, Kamal F et al. Efficacy and safety of EUS-guided biliary drainage in comparison with percutaneous biliary drainage when ERCP fails: a systematic review and meta-analysis. Gastrointest Endosc 2017; 85: 904-914

[3] Kahaleh M. Training the next generation of advanced endoscopists in EUS-guided biliary and pancreatic drainage: learning from master endoscopists. Gastrointest Endosc 2013; 78: 638-641
Bibliography

DOI https://doi.org/10.1055/s-0043-113557

Published online: 18.7.2017

Endoscopy 2017; 49: E229-E230

(c) Georg Thieme Verlag KG

Stuttgart · New York

ISSN 0013-726X
ENDOSCOPY E-VIDEOS

https://eref.thieme.de/e-videos

回局 Endoscopy E-Videos is a free access online section, reporting 靣: on interesting cases and new techniques in gastroenterological endoscopy. All papers include a high quality video and all contributions are freely accessible online.

This section has its own submission website at

https://mc.manuscriptcentral.com/e-videos 